\title{
Oxygen Capacity Measurement
}

National Cancer Institute

\section{Source}

National Cancer Institute. Oxygen Capacity Measurement. NCI Thesaurus. Code C96614.

The determination of the maximum amount of oxygen that can be combined chemically with hemoglobin in a volume of blood. 